\title{
Los «hijos de la guerra»: niños peruano-chilenos durante la ocupación de Lima (1881-1883)*
}

\section{The «Children of War»: Peruvian-Chilean Children During the Occupation of Lima (1881-1883)}

\author{
MARÍA LUCÍA VALLE VERA \\ Pontificia Universidad Católica del Perú \\ a20064651@pucp.edu.pe
}

\section{RESUMEN}

El artículo tiene como objetivo presentar una investigación sobre los hijos de hombres chilenos y mujeres peruanas concebidos y nacidos durante la ocupación de Lima (1881-1883), y brindar algunos alcances generales acerca de la situación social de aquellos niños en la Lima de finales del siglo XIX. Proponemos que la situación social de estos "hijos de la guerra" se define principalmente a través del status social de sus padres y el tipo de relación que sostuvieron (matrimonio o amancebamiento). Ante ello, en el proceso de la investigación, comprobamos que la condición de la mayoría de estos infantes en la sociedad, especialmente después de la guerra, fue adversa, ya que generalmente fueron producto de relaciones de convivencia, lo que les llevó a cargar con el estigma de ilegítimos. Además, la crisis generada por la guerra se reflejó en el status social bajo de la mayoría de sus padres. La nacionalidad que adquirieron estos niños dependió de la relación con sus padres, el destino de las familias que formaron —si permanecieron en Perú o se trasladaron a Chile-o incluso de ellos mismos.

Palabras clave: ocupación de Lima; niños peruano-chilenos; legitimidad; status social; guerra de 1879

*Agradezco especialmente a Maribel Arrelucea por su apoyo y comentarios en el proceso de elaboración del presente artículo.

HISTORIOด XLI.1 (2017): 125-157 / ISSN 0252-8894

https://doi.org/10.18800/historica.201701.004 


\section{Abstract}

This paper about the children born to Chilean men and Peruvian women during the occupation of Lima (1881-1883) provides general information about their social standing in late $19^{\text {th }}$ century Lima. It suggests that the social status of these "children of war» was defined mainly by the social status of their parents and their relationship (marriage or cohabitation). The research confirms that conditions in post-war society were adverse for most of these children, as they were usually born out of wedlock and therefore carried the stigma of illegitimacy. In addition, the crisis caused by war affected the social status of their parents. The nationality of these children depended on their relationship with their parents, the fate of their families - whether they remained in Peru or moved to Chile-and their own will.

Keywords: Occupation of Lima; Peruvian-Chilean children; legitimacy; social status; War of 1879

T a ocupación de Lima (1881-1883) fue tal vez uno de los episodios ـmás dramáticos de la guerra del Pacífico para la población peruana residente en la ciudad, no solo porque la moral de la población quedó afectada debido a la toma de la capital por el ejército invasor, sino por las invaluables pérdidas humanas y materiales que, hasta aquel momento, había generado la guerra. Por décadas, los historiadores que comentaron en sus investigaciones acerca de la vida cotidiana durante la ocupación destacaron el rechazo de la población peruana a los ocupantes chilenos debido a lo mencionado en líneas anteriores. ${ }^{1}$ Esta actitud de recelo, evidente en los testimonios de la época, es especialmente comprensible durante los primeros meses de ocupación militar, pero al prolongarse esta durante casi tres años, la convivencia se hizo inevitable.

En relación con esta última idea, recientes investigaciones han mostrado que la ocupación fue un acontecimiento complejo, pues no solo

1 Entre las investigaciones especializadas en la vida cotidiana durante la ocupación de Lima, encontramos los estudios de Rivera Serna (1984) y Guerra (1991-1996). Además, se pueden citar referencias en obras generales como la de Basadre (2005). 
provocó un ambiente de violencia y miedo, sino que, conforme se fue extendiendo, propició momentos de encuentro que tuvieron, entre sus manifestaciones más significativas, la formación de parejas de hombres chilenos y mujeres peruanas, casadas o convivientes. Después de que Oswaldo Holguín mencionara los matrimonios de chilenos y peruanas por primera vez, como parte de su estudio sobre la vida religiosa en Lima durante la ocupación chilena, ${ }^{2}$ algunos investigadores en los últimos años han retomado y analizado este aspecto tan interesante y poco comentado acerca de la convivencia entre las poblaciones peruana y chilena en Lima durante aquel período de crisis. ${ }^{3}$ No obstante, existe un rasgo de la vida de aquellas parejas al que apenas se ha prestado atención y que, por lo mismo, constituye el objeto de estudio del presente trabajo: sus hijos.

La participación de niños durante la guerra del Pacífico se ha mencionado en diversos estudios acerca del conflicto, pero aún queda pendiente un análisis más detallado del tema. En el caso de la ocupación de Lima, conocemos cierta información sobre niños que intervinieron en la defensa de la ciudad (nombres, función y procedencia), algunos de los cuales han pasado a la historia como jóvenes héroes. ${ }^{4}$ También, contamos con los testimonios de personajes ilustres que, siendo nińos, fueron testigos de los acontecimientos de la guerra y cuyas memorias ayudan a comprender el impacto de aquella en sus vidas. Como afirma Mora Ponce, a partir del análisis de los testimonios de Adriana de Gonzáles Prada y José Santos Chocano, muchos niños residentes en Lima vieron frustrado el desarrollo de su infancia y la guerra pudo generarles rezagos psicológicos. ${ }^{5}$ Además, se debe considerar a aquellos que quedaron en situación de orfandad. ${ }^{6}$

2 Holguín calculó alrededor de 30 matrimonios, lo que representó solo «2\% del total de uniones anuales estimado en quinientos» (1972-1974: 170).

3 Rodríguez Díaz 2009 y Valle 2013.

4 Basadre 2005, IX: 162; y Mora Ponce 2010: 11.

5 Mora Ponce 2011:15.

6 Cf. Mora Ponce 2011:15. En su tesis, Huamán (2009) comenta acerca del apoyo brindado a los huérfanos por comisiones de señoras limeñas, así como la situación de los hijos naturales, niños y jóvenes huérfanos de madre y padre soldado en Lima durante la guerra del Pacífico. 
No obstante, los niños producto del encuentro entre hombres chilenos y mujeres peruanas durante la ocupación han sido completamente ignorados en la historiografía. ${ }^{7}$ En ese sentido, el presente artículo tiene como objetivo introducir el tema y brindar algunos alcances generales acerca de la situación social de aquellos infantes en la Lima de finales del siglo XIX.

Para referirnos a los protagonistas de este estudio, utilizamos el término «hijos de la guerra», introducido recientemente por Charli Carpenter e Ingvill Mochmann como children born of war ${ }^{8}$ para analizar la situación de los nińos nacidos durante conflictos bélicos. A ello habría que agregar que, según la clasificación propuesta por Mochmann, los infantes sobre los que trataremos pertenecen a la categoría de «nińos de soldados de las fuerzas de ocupación». ${ }^{9}$ En este caso, los soldados pueden ser vistos como enemigos o aliados según la perspectiva de la población local. ${ }^{10}$ Si bien el ejército chileno era percibido como enemigo por parte de la población limeña, reiteramos que, en el presente artículo, analizamos los casos de niños producto de relaciones consentidas - en algunos matrimonios incluso figuran como testigos o padrinos los familiares de la novia peruana, lo que evidencia que estos también aprobaban el enlace- -11 y cuyos datos han quedado registrados en las fuentes parroquiales. Para ello, empleamos específicamente los libros de bautizos de las parroquias de Lima en el siglo XIX. Asimismo, debemos precisar que se incluyen en las cifras presentadas a los niños concebidos a partir de enero de 1881. Para definir su situación en la sociedad, nos basamos en las nociones de status y legitimidad.

7 Dediqué en mi tesis de licenciatura un apartado sobre el tema, aunque la investigación se centró en las relaciones entre hombres chilenos y mujeres peruanas (véase Valle 2013: 70-81).

8 Mochmann, Lee y Stelzl-Marx 2009: 272.

9 Mochmann propone cuatro categorías: 1) children of enemy soldiers; 2) children of soldiers from occupational forces; 3) children of child soldiers; y 4) children of peacekeeping forces (Mochmann, Lee y Stelzl-Marx, 2009: 273).

${ }^{10}$ Mochmann, Lee y Stelzl-Marx 2009: 273.

${ }^{11}$ Véase Valle 2013. Sin embargo, conviene destacar que la existencia de relaciones consentidas no anula la posibilidad de nińos producto de violaciones, una lamentable situación en contextos de guerra. 
Los «hijos de la guerra» como tema de investigación resulta muy importante, pues aquellos representan una de las principales consecuencias sociales de la ocupación y son un aspecto muy considerado recientemente en los estudios sobre conflictos armados. Este trabajo podemos inscribirlo en las corrientes de historia de la infancia y la historia social, pues, a través de las fuentes parroquiales y la legislación, proponemos un acercamiento a la experiencia de aquellos niños. En ese sentido, esperamos poder contribuir al estudio de la ocupación de Lima a partir de aquellas perspectivas, especialmente de la historia de la infancia que ha tenido escaso desarrollo en la historiografía peruana. ${ }^{12}$ Debemos ańadir que, dada la naturaleza introductoria de este trabajo, desarrollamos el tema desde una perspectiva más cuantitativa que cualitativa.

Dividimos el artículo en cinco partes. En la primera, comentamos las fuentes, metodología y marco teórico empleados para el desarrollo de este trabajo. En la segunda parte, presentamos las cifras encontradas en los libros de bautizo sobre los «hijos de la guerra" y las parroquias en las que fueron bautizados de acuerdo con el status social de sus padres. En la tercera parte, tratamos acerca de la legitimidad de aquellos niños y sus consecuentes posibilidades dentro de la sociedad limeńa. En la cuarta parte, analizamos las posibilidades de la nacionalidad que pudieron adquirir aquellos niños. Y, por último, en la quinta parte, elaboramos una reflexión final con las principales conclusiones que desprendemos de los hallazgos de este estudio.

\section{FUENTES, METODOLOGÍA Y MARCO TEÓRICO}

Como sostiene Linda Pollock, las fuentes usadas para conocer la historia de la infancia son fundamentalmente secundarias - folletos moralistas y médicos, sermones religiosos, opiniones de expertos - y la información contenida en ellas puede ser complementada con otros materiales como pinturas, literatura novelesca, relatos de viajeros, legislación, reportajes

${ }^{12}$ En la historiografía peruana, contamos con valiosos aportes para el desarrollo de esta línea de investigación, como, por ejemplo, Mannarelli 1993; Mannarelli y Rodríguez 2007; Rosas Lauro 2007; y Vergara Ormeño 2007 y 2011. 
periodísticos y algunas fuentes primarias como diarios, memorias y cartas. ${ }^{13}$ No obstante, como se ha mencionado anteriormente, en este estudio introductorio, empleamos fundamentalmente partidas de bautizo, dado que nos brindan suficientes datos para tener una noción básica sobre de la identidad de los «hijos de la guerra» y de las personas más importantes de su entorno. En efecto, en las partidas figuran el nombre del niño, su fecha de nacimiento, su estado, los nombres y nacionalidad de los padres, y los nombres de los padrinos y de los testigos — también figuraba la raza, pero de manera inconstante, por lo que no la hemos considerado una variable en nuestro análisis_- En ese sentido, dado el tipo de información que presentan, estas fuentes parroquiales también deben estimarse entre las más útiles para los estudios de la infancia.

La existencia de estos documentos durante la época de la ocupación se debe a tres motivos. En primer lugar, se debe recordar que la emisión de registros parroquiales, que daban cuenta de los acontecimientos principales de la vida de un cristiano, fue obligatoria desde el Concilio de Trento (1545-1563). ${ }^{14}$ En segundo lugar, se encuentra el importante hecho de que, durante la ocupación de Lima, las actividades religiosas no cesaron; como señala Holguín, las siete parroquias y los más de cincuenta $\mathrm{y}$ dos templos y capillas siguieron realizando sus funciones y ritos con normalidad. ${ }^{15}$ Y, en tercer lugar, se puede considerar la sensibilidad y fervor religioso de los padres de aquellos niños para quienes la crisis generada por la guerra no representó un impedimento para cumplir con aquel sacramento.

Estas fuentes resultan muy valiosas para la investigación propuesta, pues brindan datos acerca de la legitimidad y el status de aquellos niños. Así, gracias al registro del estado de los niños, en tanto reflejaba el tipo de relación que sostuvieron sus padres, fue posible determinar su legitimidad. Por un lado, los infantes registrados como legítimos fueron aquellos cuyos padres estaban casados; es decir, cumplían con los códigos de conducta

\footnotetext{
13 Pollock 1990: 38.

${ }^{14}$ Brel Cachón 1999: 93.

${ }^{15}$ Holguín 1972-1974: 168.
} 
establecidos por la Iglesia y la sociedad. Por otro lado, los niños registrados como naturales fueron aquellos cuyos padres sostenían relaciones sexuales o convivían sin estar casados, por lo que se les consideraba ilegítimos. ${ }^{16}$ La aplicación de legitimidad como variable resultó muy útil para elaborar un primer acercamiento a la situación y valoración de aquellos niños en la sociedad limeña de finales del siglo XIX, lo cual comentaremos con mayor detalle en las siguientes páginas, incluyendo algunas observaciones sobre la diferencia del trato de legitimidad entre sexos.

Además, gracias al registro de los títulos «don»o «doña» en los nombres de sus padres cuando se registró su bautizo, fue posible también determinar el status social al que pudieron pertenecer estos nińos. El status es definido como la posición de una persona en la sociedad, la cual, según Max Weber, «era generalmente adquirida por nacimiento y definida por la ley, pero se revelaba a través de su estilo de vida». ${ }^{17}$ Desde la época colonial, los títulos de «don» o «dońa» diferenciaban a los hombres y a las mujeres que pertenecían a las clases altas de la sociedad, con mejores condiciones de vida que aquellas de las clases bajas. ${ }^{18}$ Si bien Sarah Chambers, en su estudio sobre la ciudad de Arequipa en el período republicano, propone que su uso se difundió desde la época colonial hasta perder su valor en el siglo XIX, ${ }^{19}$ proponemos que, en el ámbito oficial, aquella «difusión» tuvo límites, pues comprobamos que el manejo de los títulos no fue tan generalizado entre los padres registrados en los libros de bautizo.

Para el presente estudio, empleamos la información recolectada de los libros de bautizos de seis de las parroquias de Lima: El Sagrario, San Sebastián, San Marcelo, San Lázaro, Santa Ana y la viceparroquia de Los Huérfanos. ${ }^{20}$ De los libros de bautizo, se consideraron los registros

${ }^{16}$ Entre los ilegítimos, además de los naturales (que tenían mayor categoría debido a que podían legitimarse con el matrimonio de sus padres), estaban los expósitos (abandonados) y los adulterinos.

${ }^{17}$ Citado por Burke 2000: 76.

${ }^{18}$ Lockhart 1982: 48-65.

${ }^{19}$ Chambers 2003.

${ }^{20}$ La parroquia de Santiago Apóstol, en el Cercado, fundada en 1571 en la jurisdicción de indios e incorporada a la parroquia de Santa Ana desde 1767 hasta 1882, no fue considerada en el presente estudio. 
producidos entre 1882 y 1883 , y se calculó el tiempo de concepción de los niños a partir de enero de 1881. Cabe mencionar que las cifras presentadas no son definitivas, sino un aproximado a la realidad, pues debemos considerar algunas situaciones que generan ciertos límites en relación con estas fuentes. Una primera situación es la mortalidad infantil; es decir, pudieron existir casos en los que los niños fallecían antes de que sus padres pudieran bautizarlos y, por eso, no figuran en estas fuentes consultadas. ${ }^{21}$ Una segunda situación son los errores en consignar los datos. A pesar de que la calidad de las fuentes parroquiales, en lo que respecta a la organización de información, fue mejorando con el paso del tiempo, este problema es omnipresente. ${ }^{22}$ Nunca falta un error en el registro de un dato o la omisión de información. Esta carencia, sin embargo, puede ser superada a partir de la consulta de fuentes primarias complementarias.

Como se puede comprobar por lo expuesto, los libros de bautizos nos brindan información importante para nuestro estudio. Sin embargo, para presentar un bosquejo más completo sobre la condición social de aquellos niños, también recurrimos, en el caso de Perú, al Código Civil de 1852 y la Constitución de $1860,{ }^{23}$ que tuvieron vigencia antes de la guerra del Pacífico y después de la guerra civil y el establecimiento del gobierno de Andrés A. Cáceres en 1886. Y, en el caso de Chile, la Constitución de 1833 y el Código Civil de 1855, el cual entró en plena vigencia el 1 de enero de 1857. Estas fuentes no solo permiten conocer los derechos y la valoración de estos niños en la sociedad, sino que, además, brindan información acerca de la nacionalidad con la que posiblemente se les identificó por el resto de sus vidas.

${ }^{21}$ Brel Cachón 1999: 96.

${ }^{22}$ Ib.: 94.

${ }^{23}$ La vigencia de la Constitución de 1860 se vio interrumpida en diciembre de 1879 cuando, al tomar el poder, Nicolás de Piérola expidió un Estatuto Provisorio para regular su gobierno. Sin embargo, en 1881 el gobierno provisorio de García Calderón reinstauró nuevamente la vigencia de la Constitución, la cual rigió hasta 1920 (Aguilar Rojas 2012: 8). 


\section{LOS «HIJOS DE LA GUERRA» DURANTE LA OCUPACIÓN DE LIMA}

Como sostienen Mochmann, Sabine Lee y Barbara Stelzl-Marx, las relaciones entre mujeres locales y soldados extranjeros, y los niños nacidos de ellas, son un fenómeno tan antiguo como la guerra misma. ${ }^{24}$ Reiteramos que los «hijos de la guerra», sobre los que comentaremos en los siguientes párrafos, fueron producto de relaciones consentidas, lo que supone una forma de "colaboracionismo horizontal», «sentimental» o "íntimo» ${ }^{25}$ de algunas mujeres peruanas hacia algunos hombres chilenos durante la ocupación de Lima. Es importante mencionar que ese tipo de colaboracionismo ha sido asociado principalmente a mujeres, ${ }^{26}$ y aquello se presenta en diferentes contextos históricos y geográficos. ${ }^{27}$

En los días posteriores al ingreso de las tropas chilenas a la ciudad de Lima, los habitantes de la ciudad, que se habían resguardado ante el temor de las acciones del ejército invasor, retornaron paulatinamente a sus casas y a realizar sus actividades con relativa normalidad. ${ }^{28}$ Esta vuelta a una temporal estabilidad propició los encuentros entre mujeres limeñas y soldados chilenos, y el nacimiento de niños producto de las relaciones que sostuvieron entre ellos. Los libros de bautizos de las parroquias

\footnotetext{
${ }^{24}$ Mochmann, Lee, y Stelzl-Marx 2009: 270.

${ }^{25}$ Capdevila y Virgili proponen este concepto a partir de la terminología empleada en las acusaciones contra las colaboracionistas francesas, quienes fueron sometidas a la depuración y al rapado como castigo desde 1944. Dado que los protagonistas del presente estudio son producto de relaciones consentidas, consideramos apropiada la aplicación del término (2009: 219).

${ }^{26}$ Capdevila y Virgili 2009: 219.

${ }^{27}$ Ya habíamos mencionado el caso de las mujeres francesas durante la ocupación nazi. Los estudios más representativos son los de Picaper y Norz (2004), y Virgili (2000 y 2009). En la historia de América Latina, contamos con estudios como el de Barreto Valinotti (2013), en el que analiza la situación de las mujeres paraguayas durante la ocupación del ejército brasileño durante la Guerra de la Triple Alianza. También está el trabajo de Potthast (1998), quien analiza la estructura doméstica en Paraguay antes y después de la guerra de la Triple Alianza y hace mención de las parejas de mujeres paraguayas y soldados brasileños. En el caso peruano, un acercamiento al tema nos lo brinda Mc Evoy (2000), al analizar las relaciones de género presentes en el discurso nacionalista chileno. Precisamente, la erotización de Lima deja entrever el interés que se pudo despertar entre los soldados chilenos de poseer a las mujeres limeńas.

${ }^{28}$ Guerra Martinière 1991-1996, I: 125.
} 
de Lima revelan que de 17.407 niños bautizados en Lima entre los años 1882-1883, 150 fueron hijos de padres chilenos y madres peruanas, lo que representa apenas un $0,86 \%$ del total de bautizados. Ante estas cifras, surge la cuestión de si, en su mayoría, estos niños fueron hijos de los militares chilenos que conformaron el ejército de ocupación. Las fuentes consultadas han revelado apenas cuatro casos: tres niños fueron bautizados en 1882 y uno en 1883 . No obstante, sugerimos que estas cifras no deben ser tomadas como definitivas. Lamentablemente, en la mayoría de casos revisados, no encontramos referencias de la profesión de los padres. Además, en los casos identificados, los militares pertenecían a los siguientes rangos del ejército: capitán general, sargento y subteniente. Probablemente, los soldados rasos decidieron no indicar su condición en el registro de bautizo de sus hijos con las mujeres peruanas. A lo mencionado, habría que agregarse la posibilidad de que muchos de los padres chilenos no llegaron con el ejército de ocupación, sino que fueron civiles que residieron en la ciudad durante la guerra. ${ }^{29}$

En los registros, resulta interesante la distribución de los bautizos de «hijos de la guerra» en las parroquias de Lima:

\section{Cuadro 1. Niños peruano-chilenos en las parroquias de Lima (1882-1883)}

\begin{tabular}{lc}
\hline Parroquia & Cantidad de nińos (1882-1883) \\
\hline El Sagrario & 36 \\
San Marcelo & 8 \\
San Lázaro & 20 \\
Santa Ana & 45 \\
San Sebastián & 19 \\
Los Huérfanos & 22 \\
\hline Total & 150 \\
\hline
\end{tabular}

Fuentes: Archivo Arzobispal de Lima [en adelante AAL]. Libros de bautizos de las parroquias: El Sagrario, Santa Ana, San Lázaro, San Marcelo, San Sebastián y la viceparroquia de Los Huérfanos (1882-1883).

${ }^{29}$ Según el censo de 1876, residían en la provincia de Lima 1323 ciudadanos chilenos: 720 hombres y 603 mujeres (Ministerio de Gobierno, Policía y Obras Públicas 1878, VI: 365). 
Como se puede observar, entre 1882-1883, la mayor cantidad de niños peruano-chilenos fueron bautizados en Santa Ana (45), seguida por El Sagrario (36), Los Huérfanos (22), San Lázaro (20), San Sebastián (19) y San Marcelo (8). Las diferencias identificadas en la cantidad de registros en las parroquias nos llevan a considerar la posibilidad de que el status social de los padres jugó un rol fundamental en la elección de las mismas para realizar los bautizos. Para sostener esta asociación espaciostatus social, nos remitimos a la configuración de la ciudad de Lima.

Lima, en el siglo XVI, fue edificada y organizada siguiendo la disposición de damero. En esa distribución, la Plaza Mayor se consolidó como núcleo de la ciudad, pues en su entorno se ubicaron los edificios más importantes del gobierno colonial: la Catedral, el Palacio de Gobierno y el Ayuntamiento. Como sostiene Aldo Panfichi, la distribución de los lotes del damero estaba definida por la correlación entre status social de los individuos y la distancia física de su residencia en la Plaza Mayor. Cuanto más lejos resida una persona de la plaza, más bajo es su status social. ${ }^{30}$ A ello, habría que agregarse la propuesta de María Emma Mannarelli de que en la época colonial la ubicación de las parroquias refleja esta distribución. ${ }^{31}$ En ese sentido, proponemos que los padres que bautizaron a sus hijos en parroquias alejadas de la plaza pertenecieron generalmente a los estratos más bajos de la sociedad, mientras que aquellos que los bautizaron en las parroquias más cercanas eran de un estrato más alto.

Es importante mencionar que si bien las batallas de San Juan y Miraflores, el 13 y el 15 de enero de 1881, tuvieron como consecuencia la destrucción de algunas residencias y espacios urbanos — la zona más afectada resultó ser el balneario de Chorrillos_, ${ }^{32}$ la organización de la ciudad no fue modificada sino hasta después de la guerra. Y si bien, desde la fundación de Lima, la distribución de la población de los diferentes status e incluso razas no fue rígida en los distintos espacios de la ciudad, ${ }^{33}$ para aquel tiempo

30 Panfichi 1995: 19.

${ }^{31}$ Mannarelli 1993: 83-84.

32 Ramón Joffré 2004: 18.

33 De hecho, hacia finales del siglo XIX, en Lima se realizaron modificaciones en el espacio de la ciudad, y la diversificación social y étnica en los diversos espacios se hizo más evidente (Panfichi 1995: 24). 
todavía es posible detectar tendencias de cierto tipo de población en las parroquias, la cual estuvo definida desde la época colonial. ${ }^{34}$

En ese sentido, siguiendo a Mannarelli, proponemos que el bautizo de niños en una determinada parroquia sí es un indicador de status. Esta información a su vez puede ser contrastada con los datos proporcionados por los registros de bautizo en los que figuran los títulos usados por los padres de los niños peruano-chilenos. Recordemos que, para definir el status social de los padres en esta investigación, recurrimos al uso de los títulos «don» y «dońa». Identificamos que los padres pertenecientes al status social alto son aquellos que, en los registros parroquiales, usaron los títulos mencionados; los que pertenecieron al status social bajo no usaron los títulos; y los identificados como pertenecientes a un status social mixto son aquellos padres que pertenecieron a estratos sociales distintos.

\section{Gráfico 1. Status de los padres de los niños peruano-chilenos (1882-1883)}

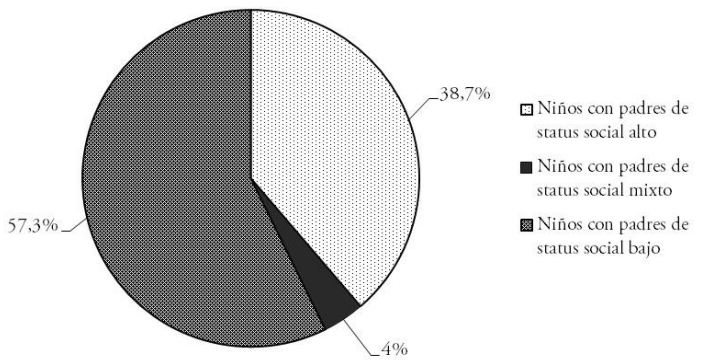

Fuentes: AAL, Libros de bautizos de las parroquias: El Sagrario, Santa Ana, San Lázaro, San Marcelo, San Sebastián y la viceparroquia de Los Huérfanos (1882-1883).

Como se puede apreciar en el gráfico 1, la mayoría de niños peruanochilenos tuvieron padres de status social bajo. Hallamos 86 casos que representan el 57,3\% del grupo estudiado. Luego, encontramos 58 casos de niños cuyos padres pertenecieron a un status social alto, el 38,7\% del grupo, y apenas 6 casos de niños cuyos padres pertenecieron a estratos 
sociales diferentes, el 4\%. Resulta interesante, además, observar cómo los casos se distribuyen entre las parroquias de Lima:

\section{Cuadro 2. Status de los padres de los nińos peruano-chilenos en las parroquias de Lima (1882-1883)}

\begin{tabular}{lcccccc}
\hline & $\begin{array}{c}\text { El } \\
\text { Sagrario }\end{array}$ & $\begin{array}{c}\text { San } \\
\text { Marcelo }\end{array}$ & $\begin{array}{c}\text { San } \\
\text { Lázaro }\end{array}$ & $\begin{array}{c}\text { Santa } \\
\text { Ana }\end{array}$ & $\begin{array}{c}\text { San } \\
\text { Sebastián }\end{array}$ & $\begin{array}{c}\text { Los } \\
\text { Huérfanos }\end{array}$ \\
\hline $\begin{array}{l}\text { Nińos de padres } \\
\text { de status } \text { alto }\end{array}$ & 18 & 8 & 11 & 10 & 9 & 2 \\
$\begin{array}{l}\text { Nińos de padres } \\
\text { de status } \text { mixto }\end{array}$ & 1 & 0 & 0 & 4 & 1 & 0 \\
$\begin{array}{l}\text { Nińos de padres } \\
\text { de status bajo }\end{array}$ & 17 & 0 & 9 & 31 & 9 & 20 \\
\hline Total & 36 & 8 & 20 & 45 & 19 & 22 \\
\hline
\end{tabular}

Fuentes: AAL, Libros de bautizos de las parroquias: El Sagrario, Santa Ana, San Lázaro, San Marcelo, San Sebastián y la viceparroquia de Los Huérfanos (1882-1883).

Si se observa el caso de la parroquia Santa Ana, en la que fueron bautizados más nińos, se puede advertir que la mayoría tuvo padres que pertenecieron al estrato bajo de la sociedad, y esto no debe sorprendernos. Recordemos que la parroquia de Santa Ana (erigida en 1550) se ubicaba en el tercer cuartel de la ciudad, junto al hospital militar que llevaba su mismo nombre. Además, estos se encontraban muy cerca del pueblo de indios del Cercado, establecido lejos de la ciudad en 1571, y representó uno de los núcleos de expansión de Lima a finales del siglo XIX. A pesar de ser construido inicialmente para concentrar a la población indígena, con el pasar de los años fue habitado por miembros de otros grupos populares, como negros libertos, artesanos, blancos pobres, entre otros. ${ }^{35}$ Esta tendencia se repite en la viceparroquia de Los Huérfanos, con la diferencia de que en ella no se realizaron bautizos de niños con padres de otro status social. Esta parroquia se ubicaba también lejos del centro de la ciudad, al lado del asilo para huérfanos. ${ }^{36}$

\footnotetext{
35 Panfichi 1995: 22.

${ }^{36}$ Hünefeldt 2000: 46-479.
} 
La situación en las parroquias de El Sagrario y San Lázaro fue distinta, pues encontramos registrados mayor cantidad de niños cuyos padres tuvieron un status social alto, aunque lo que llama la atención es que la diferencia entre la cantidad de infantes con padres de status social bajo sea mínima, de apenas un caso. Es importante mencionar que El Sagrario, al ser viceparroquia de la Catedral, se encontraba ubicada en el segundo cuartel y en el mismo espacio de la Plaza Mayor. La parroquia de San Lázaro, en cambio, fundada en 1563 y viceparroquia de El Sagrario hasta 1756 cuando se volvió independiente, ${ }^{37}$ se localizaba lejos del centro de la ciudad —en el quinto cuartel y cruzando el río Rímac- Esta última parroquia se encontraba anexada al hospital del mismo nombre para realizar los servicios religiosos. Además, era frecuentada por la población negra que habitaba el Arrabal de San Lázaro. Así, a pesar de las tendencias, los hallazgos muestran la posibilidad de movilidad social que existía en la época.

Por último, el caso de la parroquia San Sebastián, en la que encontramos registrados únicamente niños con padres de status social alto, es muy particular respecto a los otros, pero previsible. La parroquia, fundada en 1561, se encontraba en el primer cuartel y cerca del centro de poder de la ciudad, la Plaza Mayor, por lo que, desde sus inicios, era frecuentada por ciudadanos de la élite limeña.

Para concluir este apartado, cabe señalar que la existencia de hijos de chilenos nacidos en el contexto de la ocupación de Lima era conocida en Chile. Milton Godoy comenta que aquella situación generó preocupación en Chile, puesto que no había ninguna normativa al respecto. Precisamente, en una carta enviada por Eloy Caviedes al presidente de Chile, Domingo Santa María, con fecha de 20 de mayo de 1883, aquel señala que había entre 9000 y 11.000 hijos de chilenos en todo el territorio peruano. ${ }^{38}$ Para obtener una cifra más exacta, se propuso la redacción de una ley que los declarara chilenos y les otorgara una serie de beneficios como inmunidades, títulos, franquicias y prerrogativas. ${ }^{39}$

\footnotetext{
${ }^{37}$ Fuentes 1988: 24; y Middendorf 1973: 194.

${ }^{38}$ Godoy Orellana 2017.

${ }^{39}$ Citado en Godoy Orellana 2017.
} 
Es notoria la diferencia entre las cifras presentadas por Caviedes y las expuestas en los párrafos anteriores a partir del análisis de las fuentes parroquiales limeñas. Sin embargo, resulta importante el hecho de que aquella realidad de la ocupación fuera informada al gobierno chileno, ante lo cual queda pendiente un análisis sobre las acciones concretas del mismo. ${ }^{40}$

\section{LA LEGITIMIDAD DE LOS «HIJOS DE LA GUERRA»}

La legitimidad de los niños peruano-chilenos nacidos durante la ocupación de Lima también requiere nuestra atención, pues aquel aspecto influyó en la forma en la que fueron percibidos en la sociedad limeña de finales del siglo XIX. Para introducir el tema, presentamos el gráfico 2:

Gráfico 2. Legitimidad de los niños peruano-chilenos nacidos entre 1882-1883

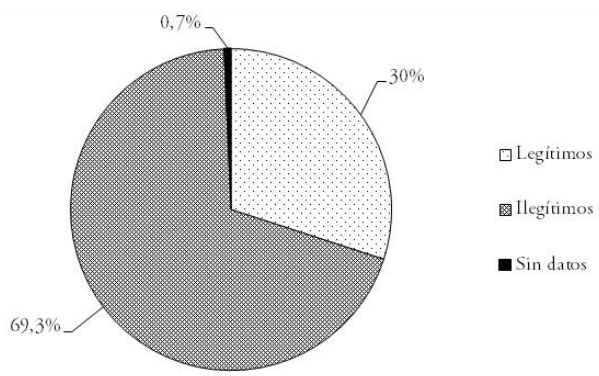

Fuentes: AAL, Libros de bautizos de las parroquias: El Sagrario, Santa Ana, San Lázaro, San Marcelo, San Sebastián y la viceparroquia de Los Huérfanos (1882-1883).

En los registros de bautizos, encontramos 104 niños peruano-chilenos ilegítimos, el 69,3\% del total, y 45 legítimos, el 30\%. Hay, además, un caso en el que no se ha podido identificar el estado del niño, el 0,7\%. Cabe mencionar que, para describir la situación de estos infantes en Lima, recurrimos como complemento principalmente a lo establecido

${ }^{40}$ Quedan pendiente los comentarios de Godoy Orellana sobre el alcance de aquellos nacimientos en Perú y las acciones concretas del gobierno chileno respecto a aquella realidad de la ocupación, lo cual tratará en su próxima publicación indicada en la bibliografía del presente artículo. Agradezco su colaboración al brindarme esta información para complementar este primer acercamiento al tema desde fuentes peruanas. 
por el Código Civil de 1852. Así, pudimos constatar que todos los niños identificados como ilegítimos aparecen registrados como «naturales»; esto quiere decir que fueron concebidos durante el tiempo en el que sus padres no tenían ningún impedimento para casarse. ${ }^{41}$ Cabe mencionar que, entre los ilegítimos, los naturales tuvieron mejor categoría que los adulterinos y expósitos, pues estos podían ser legitimados a través del matrimonio de los padres. ${ }^{42}$

Por otro lado, el hecho de encontrar mayor cantidad de niños ilegítimos estuvo influenciado por el contexto de desorden y crisis generado por la guerra. Como resalta Mannarelli, muchos historiadores han señalado que algunas de las lamentables consecuencias de la guerra del Pacífico fueron precisamente el aumento de la prostitución, la cantidad de niños nacidos fuera del matrimonio y la caída de la tasa matrimonial. ${ }^{43}$ Esta tendencia también refleja una característica propia de Lima: se trata de una ciudad con altos índices de ilegitimidad. De hecho, estos aumentan en el transcurso del siglo XIX. A partir de la consulta de testamentos, Christine Hünefeldt sostiene que casi una quinta parte $(18,2 \%)$ de los niños de Lima nacieron fuera del matrimonio entre 1810 y $1900 .{ }^{44} \mathrm{El}$ porcentaje de ilegitimidad era de $17,8 \%$ entre 1810 y 1820 y entre 1840 y 1860 , y aumentó a 19,3\% hacia el final de siglo. ${ }^{45} \mathrm{Si}$ bien la información presentada proviene de distintas fuentes y puede presentar variantes, es dable proponer que el nivel alto de ilegitimidad de los «hijos de la guerra» es una muestra de esta tendencia remarcada por Hünefeldt. ${ }^{46}$

Para sustentar más esta última propuesta, contamos con lo señalado por José González Clavero. Según los registros de bautizo consultados

${ }^{41}$ Código Civil del Perú de 1852 [s.a.]: 46.

${ }^{42}$ Ib.: 51 .

${ }^{43}$ Mannarelli 2004: 350.

${ }^{44}$ Hünefeldt 2000: 25.

${ }^{45} \mathrm{Ib}$.

${ }^{46}$ Es importante señalar que los bajos niveles de ilegitimidad señalados por Hünefeldt (2000) responden a la naturaleza de las fuentes que ella emplea para realizar su estudio: los testamentos. Era muy común que muchos padres reconocieran a sus hijos ilegítimos antes de morir, ya sea para redimirse de sus pecados o para organizar la distribución de sus herencias. 
por este último, había 1797 ilegítimos y 1576 legítimos en la ciudad de Lima cuando culminó la ocupación. ${ }^{47}$ Es decir, del total de bautizados registrados (3373), 53,3\% eran ilegítimos y 46,7\%, legítimos. Se tiene, entonces, que en la ciudad de Lima, después de la guerra, la tendencia a un incremento de la ilegitimidad continuaba. ${ }^{48}$ Otro dato que brinda Clavero, y que se comprobó en la presente investigación, es la diferencia que existió del grado de legitimidad entre sexos. ${ }^{49}$ A continuación, en el cuadro 3, podemos apreciar la comparación entre la información recolectada acerca de los «hijos de la guerra» en las fuentes parroquiales revisadas para el presente estudio y la información presentada por Clavero.

Cuadro 3. Sobre la diferencia de legitimidad entre sexos

\begin{tabular}{lcccccc}
\hline & $\begin{array}{c}\text { Legitimidad de niños } \\
\text { y niñas peruano- } \\
\text { chilenos (1882-1883) }\end{array}$ & $\begin{array}{c}\text { Legitimidad de niños } \\
\text { y niñas peruano- } \\
\text { chilenos (1884-1886) }\end{array}$ & \multicolumn{2}{c}{$\begin{array}{c}\text { Legitimidad en Lima } \\
\text { en 1884 registrada } \\
\text { por Clavero (1885) }\end{array}$} \\
\hline Mujeres & Cantidad & $\%$ & Cantidad & $\%$ & Cantidad & $\%$ \\
\hline Legítimas & 27 & 34,2 & 6 & 20,7 & 814 & 47,5 \\
Ilegítimas & 52 & 65,8 & 23 & 79,3 & 900 & 52,5 \\
Total & 79 & 100 & 29 & 100 & 1714 & 100 \\
\hline Hombres & Cantidad & $\%$ & Cantidad & $\%$ & Cantidad & $\%$ \\
\hline Legítimos & 51 & 71,8 & 11 & 33,3 & 762 & 45,9 \\
Ilegítimos & 19 & 26,8 & 21 & 63,7 & 897 & 54,1 \\
No datos & 1 & 1,4 & 1 & 3 & -100 & - \\
Total & 71 & 100 & 33 & 100 & 1659 & 100 \\
\hline
\end{tabular}

Fuentes: AAL, Libros de bautizos de las parroquias: El Sagrario, Santa Ana, San Lázaro, San Marcelo, San Sebastián y la viceparroquia de Los Huérfanos (1882-1886) y Clavero 1885: 35.

\footnotetext{
${ }^{47}$ Clavero 1885.

${ }^{48}$ En el caso chileno, la ilegitimidad también alcanzó altos niveles en el siglo XIX, especialmente a partir de 1880 (Rojas Flores 2010: 125).

${ }^{49}$ Clavero 1885.
} 
Tanto los registros de bautizos como los estudios de Clavero coinciden en señalar que los índices de ilegitimidad más altos corresponden a niñas. En los años de la ocupación chilena, de las 79 infantas registradas, el $65,8 \%$ fueron ilegítimas, mientras que, en el caso de los varones, de un total de 71 , solo un $26,8 \%$ fueron registrados como ilegítimos (naturales). En el período posterior a la ocupación, de 1884 a 1886, el porcentaje de ilegitimidad aumentó para el caso de hombres y mujeres; sin embargo, la diferencia entre ambos tuvo la misma tendencia. De las 29 niñas registradas, el 79,3\% fueron ilegítimas (naturales), mientras que, de los 33 niños registrados, 63,7\% fueron ilegítimos (naturales). Clavero, quien presentó cifras considerando a todos los niños registrados en los libros de bautizo en 1884, mostró la tendencia mencionada. De 1714 mujeres registradas, el 52,5\% eran ilegítimas y, de 1659 hombres registrados, $54,1 \%$ eran ilegítimos. Desde inicios del siglo XIX, la diferencia de cifras de legitimidad entre hombres y mujeres era muy notoria. Hünefeldt señala que, a inicios del siglo XIX, 20,1\% de hombres se habían manifestado como ilegítimos en sus licencias matrimoniales, en contraste con el $24,6 \%$ de mujeres que habían declarado ser de la misma condición. ${ }^{50}$ Con el pasar de los años, hacia finales del siglo XIX, esta diferencia aumentó, ya que se registraron como ilegítimos 13,2\% de hombres a diferencia de 20,5\% de mujeres. ${ }^{51}$ Asimismo, presentamos las cifras de la legitimidad de los niños peruano-chilenos nacidos después de la ocupación entre los años 1884-1886 y comprobamos que la diferencia de ilegitimidad entre sexos se mantuvo con mayor tendencia en las mujeres $(79,3 \%)$ que hombres $(63,7 \%)$.

No se conoce con certeza el origen de esta diferencia demostrada con distintas fuentes, pero lo que se puede predecir es que la mayoría de los «hijos de la guerra» no tuvo un futuro fácil, debido a que la ilegitimidad continuaba siendo un estigma social. Además, como señala Carlos Ramos, el Código Civil de 1852 también se encargó de hacer sentir una marcada diferencia entre la condición de los hijos legítimos

\footnotetext{
${ }^{50}$ Hünefeldt 2000: 24.

${ }^{51} \mathrm{Ib}$.
} 
y los ilegítimos naturales..$^{52}$ Por ejemplo, a diferencia de los hijos legítimos, que se encontraban bajo la patria potestad del padre, los hijos naturales dependían de su madre. El padre tenía la obligación de dar alimento a "toda clase de hijos» (se incluyen a los diferentes tipos de hijos ilegítimos). ${ }^{53}$ Sin embargo, los hijos naturales, al ser ilegítimos, no tenían derecho a exigir alimentos en los siguientes casos: cuando hubiesen cumplido los veintiún años, a no ser que se encontraran enfermos; cuando se les hubiese asegurado la subsistencia hasta aquella edad; y cuando se les hubiese enseñado alguna profesión, arte u oficio con el que pudieran subsistir. ${ }^{54}$ Respecto de las herencias, los hijos ilegítimos eran herederos de sus madres cuando ellas no contaban con hijos legítimos. ${ }^{55}$ Estos también podían heredar a los parientes maternos, salvo que fueran adulterinos. ${ }^{56}$ Por otro lado, si los hijos ilegítimos eran reconocidos por sus padres, podían heredar solo el quinto de su herencia, si aquel tenía descendientes legítimos; la mitad, cuando no tuviera ascendientes legítimos; y todo, si el padre no contaba con descendientes y ascendientes legítimos, y su madre no participaba de la herencia. ${ }^{57}$ En cambio, los hijos legítimos eran herederos y los primeros en ser llamados a la sucesión. ${ }^{58}$ En el caso particular de las niñas ilegítimas, no solo estaban sometidas a los dictámenes del Código Civil Peruano de 1852 respecto a la potestad, alimentos y herencia, sino que tampoco tenían derecho a recibir una dote, dado que ese era el deber que un padre debía asumir con sus hijas legítimas. ${ }^{59}$ Para poder superar su condición adversa en la sociedad, las mujeres ilegítimas podían casarse con hombres legítimos. ${ }^{60}$

\footnotetext{
52 Ramos 2005: 287.

53 Código Civil del Perú de 1852 [s.a.]: 46.

${ }^{54}$ Ib.: $50-51$

55 Ib.: 154 .

${ }^{56} \mathrm{Ib}$

57 Ib.: 153.

58 Ib.: 151 .

59 Ib.: 167.

${ }^{60}$ Hünefeldt (2000: 25) señala que en las licencias matrimoniales un alto índice de mujeres ilegítimas se casa con hombres legítimos. Esto pone en evidencia el deseo de estas mujeres de limpiar su descendencia del estigma social con el que cargaron.
} 
Después de comentar la diferencia de la legitimidad de los «hijos de la guerra» entre sexos, resulta importante tratar también la diferencia entre ellos de acuerdo con el status social de sus padres:

Cuadro 4. Legitimidad de los nińos peruano-chilenos y el status social de sus padres (1882-1883)

\begin{tabular}{lcc}
\hline & Niños legítimos & Niños ilegítimos \\
\hline Padres de status social alto & 24 & 34 \\
Padres de status social mixto & 3 & 3 \\
Padres de status social bajo & 18 & 67 \\
\hline Total & 45 & 104 \\
\hline
\end{tabular}

Fuentes: AAL, Libros de bautizos de las parroquias: El Sagrario, Santa Ana, San Lázaro, San Marcelo, San Sebastián y la viceparroquia de Los Huérfanos (1882-1883).

Definitivamente, la tendencia de ilegitimidad de hijos se impone entre los diferentes grupos sociales identificados; sin embargo, resulta necesario destacar algunos detalles en cada grupo. Primero, entre los niños legítimos e ilegítimos con padres de status social alto, la diferencia es apenas de diez casos. Probablemente, los padres de status alto intentaron cumplir las convenciones sociales de la época con la facilidad que les daba su posición económica, aunque muchos seguramente se vieron impedidos de ello debido al contexto. Segundo, entre los niños cuyos padres pertenecieron a estratos sociales distintos, no existió diferencia. Tercero, la diferencia entre los niños legítimos e ilegítimos de padres de status social bajo resulta mucho más notoria que en los otros grupos. Este último resultado no llama la atención, no solo por el ambiente de crisis generado por la guerra, sino debido a la relación ilegitimidad-grupos populares que se puede identificar desde la época colonial.

Como ya se ha mencionado, Lima era una ciudad con niveles de ilegitimidad altos, especialmente en los grupos populares en los que las parejas, a diferencia de las que pertenecían a los grupos sociales de élite, no fueron objeto de la presión social para contraer matrimonio. Como señala Mannarelli, «las distancias sociales entre los grupos obstaculizaban 
la transmisión de formas de regulación social como el matrimonio. A los grupos dominantes, con excepción de la iglesia y solo en algunos casos, les interesaba poco el control de la moral sexual de los subalternos. La presión social sobre estos era insignificante en relación al matrimonio». ${ }^{61}$

Ante lo mencionado, puede surgir la pregunta de si la ilegitimidad de los niños influyó negativamente en la relación con sus padres, lo cual se puede manifestar a través del abandono o desentendimiento del parentesco con el niño dada la falta de un compromiso formal entre los padres. Mannarelli, en su estudio sobre la ilegitimidad en el período colonial, sugiere que, dado lo común que era la ilegitimidad en Lima, sí fue posible que en la sociedad se desarrollara una experiencia afectiva frente a los niños ilegítimos. ${ }^{62}$ No obstante, nuevamente debemos considerar el contexto. Aunque los chilenos residentes en Lima antes de la guerra estuvieran familiarizados con estas actitudes frente a la ilegitimidad, es posible que los chilenos que llegaron con el ejército de ocupación tuvieran otra perspectiva. ¿Cómo era tratado el asunto de la ilegitimidad en Chile? En aquel país, desde mediados del siglo XIX, el Estado fomentó una ordenación social sustentada en el matrimonio y la familia nuclear. ${ }^{63}$ Es decir, como afirma Jorge Rojas Flores, «la imagen de una familia moderna, conformada por una pareja casada y sus hijos reconocidos y debidamente bautizados, comenzó a fortalecerse, a nivel ideológico». ${ }^{64}$ No obstante, el modelo de familia nuclear no logró imponerse, sino que existieron otros modelos, como la convivencia, ampliadas y monoparentales. ${ }^{65}$ En similitud con el caso peruano, en Chile la situación de ilegitimidad era muy común. Como señala Sergio Vergara Quiroz, en el siglo XIX, entre un tercio y un quinto de los niños bautizados en algunas regiones tenían esa condición. ${ }^{66}$ Asimismo, la ilegitimidad estaba presente en todos los estratos sociales, aunque las sanciones ante

\footnotetext{
${ }^{61}$ Mannarelli 2004: 338.

62 Ib.: 339.

${ }^{63}$ Vergara Quiroz 1993, I: 184; esta también afectó al ejército.

${ }^{64}$ Rojas Flores 2010: 123.

${ }^{65} \mathrm{Ib}$.

${ }^{66}$ Vergara Quiroz 1993, I: 141.
} 
ella se producían en diferentes grados. En las familias de status alto, las sanciones eran mucho más rígidas debido a la moral dominante, especialmente en el caso de las mujeres. El escándalo era resguardado de la forma más discreta posible. Se podía llegar a la reclusión de la mujer que había cometido la falta y, en otros casos, se entregaba el hijo a otra familia. Para los varones, la situación era muy distinta, pues, cuando aquellos tenían hijos con mujeres de status social bajo, esto era aceptado e, incluso, podía ser tomado como una muestra de poder. En el caso de los sectores populares, las relaciones de convivencia o amancebamiento eran muy comunes, por lo que - aunque existieron mecanismos de apoyo a los niños ilegítimos y sus padres, como la «adopción temporal»— el estigma de la ilegitimidad no tuvo mucha influencia. ${ }^{67}$

Sin embargo, cuando el Código Civil de 1855 entró en vigencia, el 1 de enero de 1857, fueron planteadas mayores diferencias entre legítimos e ilegítimos. Comenta Vergara Quiroz que el Código «procuró hacer distintiva y tajante la exclusión del hijo ilegítimo de cualquier protección, dejando a los nacidos en esa calidad en la más completa orfandad jurídico, ya que no tenían, según el Código, ni padres ni parientes, ni derechos hereditarios de ningún tipo. Además que traían sobre la madre y su familia el deshonor y la vergüenza». ${ }^{68}$ También, dentro del grupo de ilegítimos, se establecieron cambios. Por ejemplo, fue más difícil el reconocimiento de la paternidad de los hijos naturales. A estos cambios habría que agregarse que el cuidado del niño también fue necesario para comprobar la filiación. En ese sentido, el modelo de familia nuclear desplazó progresivamente la posibilidad de circulación o entrega temporal de niños. ${ }^{69}$

Como se puede apreciar, los chilenos también estaban familiarizados con la situación de ilegitimidad y, sobre todo, ya se había comenzado a inculcar la preocupación por la crianza de hijos ilegítimos. Si bien no todas las parejas estuvieron interesadas en legitimar su relación e hijos a través de un matrimonio, existió la posibilidad de legalizar el vínculo con sus hijos

\footnotetext{
${ }^{67}$ Rojas Flores 2010: 123-124.

${ }^{68}$ Vergara Quiroz 1993, I: 143

${ }^{69}$ Rojas Flores 2010: 124-125.
} 
ilegítimos a partir de su reconocimiento. De acuerdo con el Código Civil Peruano de 1852, el reconocimiento de los hijos naturales por sus padres debía realizarse en los «registros de nacidos, o en la partida de bautismo, o en escritura pública o en testamento». ${ }^{70}$ En Chile, Código Civil de 1857 señala que el reconocimiento de los hijos naturales también procedía por los mismos medios: «en escritura pública, en la inscripción de nacimiento del hijo o en acto testamentario». ${ }^{71}$ De hecho, este trámite influía de forma muy positiva en la vida de aquellos nińos, puesto que, si aquellos recibían apoyo del padre $u$ otro miembro de sus familias paternas, aquel respaldo social podría ayudarlos a superar las adversidades de tipo jurídico y moral que representaba su condición de ilegítimos. ${ }^{72}$ El registro de aquellos infantes se realizaba a través de la firma del padre en las partidas de bautismo. Aquí, el poder de la paternidad debe ser destacado. Así lo menciona Mannarelli para la época colonial: «La palabra masculina fue considerada cierta en el momento de inscribir a sus hijos en el registro parroquial». ${ }^{73}$

En los años de la ocupación militar, encontramos once registros de bautizo firmados por padres chilenos. De ellos, siete son de hijos naturales. ${ }^{74} \mathrm{Y}$ de esos siete, son tres los casos de padres de status alto. El primero es Daniel Escobar, quien firmó el registro de bautizo de la hija que tuvo con Luisa Benavides, llamada Ema Rosario $;^{75}$ el segundo

${ }^{70}$ Código Civil del Perú de 1852 [s.a.]: 47.

${ }^{71}$ Código Civil de Chile de 1857 1961: 101.

${ }^{72}$ Rojas Flores 2010: 143-144.

${ }^{73}$ Mannarelli 2004: 340.

${ }^{74}$ Entre estos casos se ha encontrado un registro de bautizo de la parroquia San Marcelo, con fecha de 28 de mayo de 1882, el cual es firmado por el padrino a petición del padre para dejar constancia de que este último reconoce a su hija. Se trata del registro de bautizo de Juana Rosa Raquel, hija natural de don Félix Matos, oriundo de Concepción de Chile (AAL, Parroquia San Marcelo, Libro de bautizos de espańoles n. 23 [1882-1889], n. ${ }^{\circ}$ 237, f. 81).

75 Registro de bautizo del 26 de mayo de 1882, AAL, Parroquia San Sebastián, Libro de bautizos de españoles n. ${ }^{\circ} 25$ (1881-1885), n. ${ }^{\circ}$ 560, f. 166. Según los registros, Daniel Escobar tuvo otro hijo natural llamado Elías Daniel. Aunque la madre del niño es también Luisa Benavides, en este caso no se encuentra la firma del padre; Registro de bautizo del 8 de octubre de 1883, AAL, Parroquia San Sebastián, Libro de bautizos de espańoles n. ${ }^{\circ} 25$ (1881-1885), n. ${ }^{\circ} 1151$, f. 339. 
es Manuel A. Fuenzalida, quien tuvo una hija llamada Zoila Virginia con Agustina Goudy; ${ }^{76}$ y el tercero es Luis Víctor Gana, quien, con Amalia Ponce, tuvo una hija llamada Luisa Amalia. ${ }^{77}$ Por otro lado, un caso de status social mixto es el de Justino Gac, oriundo de Valparaíso, quien firmó el registro de bautizo de Rosa Julia, la hija que tuvo con Josefa Salazar. ${ }^{78}$ Y, finalmente, entre los casos de padres de status social bajo con hijos naturales, se encuentran Ricardo Alfré, quien tuvo un hijo con Micaela Urbina llamado Adolfo Segundo; ${ }^{79}$ y Juan Sepúlveda, quien, con Elvira Rivera, tuvo una hija llamada Melchora María Rosa. ${ }^{80}$

No podemos terminar esta sección sin mencionar el único caso de reconocimiento de hijo ilegítimo en el que se ha identificado al padre entre los soldados extranjeros. Se trata del capitán segundo ayudante del Estado Mayor General del ejército chileno, Francisco Alberto de la Gándara y Borkesky, quien, el 18 de setiembre de 1882, firmó el registro de bautizo de su hijo Carlos Alberto, pero sin que figure el nombre de la madre. ${ }^{81}$ Los padrinos del niño fueron Emilio Puyó, ciudadano francés, e Isabel Gignorex, en representación de Rafaela Gonzales de Valdéz. Carlos Alberto, nacido el 2 de setiembre, ${ }^{82}$ habría sido concebido aproximadamente en diciembre de 1881, cuando la ocupación de la ciudad estaba consolidada y el presidente provisional García Calderón se encontraba deportado en Chile.

${ }^{76}$ Registro de bautizo del 2 de octubre de 1833, AAL, Parroquia San Lázaro, Libro de bautizos de españoles n. ${ }^{\circ} 33$ (1883-1886), f. 203.

77 Registro de bautizo del 2 de octubre de 1883, AAL, Parroquia Santa Ana, Libro de bautizos de españoles n. ${ }^{\circ} 38$ (1882-1885), f. 157.

${ }^{78}$ Registro de bautizo del 6 de agosto de 1882, AAL, Parroquia San Sebastián, Libro de bautizos de españoles n. 25 (1881-1885), n. ${ }^{\circ}$ 632, f. 183.

${ }^{79}$ Registro de bautizo del 20 de setiembre de 1882, AAL, Viceparroquia de Los Huérfanos, Libro de bautizos de espańoles n. 24 (1881-1883), n. ${ }^{\circ} 705$, f. 118v.

${ }^{80}$ Registro de bautizo del 20 de enero de 1883, AAL, Viceparroquia de Los Huérfanos, Libro de bautizos de espańoles n. ${ }^{\circ} 24$ (1881-1883), n. ${ }^{\circ}$ 902, f. 151.

${ }^{81}$ AAL, Parroquia El Sagrario, Libro de bautizos de españoles n. ${ }^{\circ} 31 \mathrm{~A}$ (del 2 de abril de 1882 al 14 de abril de 1886), f. 39.

${ }^{82}$ Este caso fue expuesto en mi tesis de licenciatura (Valle 2013: 80 y 102-104), pero en la presente publicación se agregan otros datos más precisos, como la fecha del registro y el nombre del niño. 
Lo que sin duda llama la atención es el anonimato de la madre, pues genera algunas teorías. De ser peruana y pertenecer a un status alto, su anonimato probablemente esté relacionado con las sanciones sociales que las familias de dicha condición aplicaban a las mujeres que se involucraban en relaciones ilegítimas. Para evitar el escándalo, como señala Mannarelli para la época colonial, «no existe ley escrita o pública que sancione la conducta sexual de las mujeres aristócratas. Las actitudes privadas, domésticas son las que entran en acción». ${ }^{83}$ La carrera militar de Gándara y Borkesky aún se encontraba en desarrollo y probablemente el grado que ostentaba no fue suficiente para la familia de la mujer con la que se involucró, sumado al miedo por las futuras represalias. Existe la posibilidad de que el capitán chileno, una vez finalizada la guerra, regresara a Chile y dejara a su hijo bajo el cuidado de sus padrinos; pero también pudo haberlo llevado consigo para formar una familia con una mujer chilena. Otra posibilidad es que la madre de Carlos Alberto haya sido chilena, tal vez alguna de las cantineras que viajaron acompañando al ejército. No obstante, aquello no supondría un motivo suficientemente significativo para que su identidad permanezca en secreto. Lamentablemente, no contamos con información para completar la historia, pero este caso resulta muy interesante y representativo.

A pesar de la existencia de estos registros firmados, su significancia es mínima en comparación con el resto de registros consultados para la presente investigación. ¿El contexto de ocupación influyó en esta cifra tan baja? Probablemente sí. Es cierto que hubo soldados chilenos que optaron por desertar y quedarse en Lima con sus nuevas familias; así lo comenta en sus memorias el soldado chileno José Miguel Varela: «También se dieron muchos casos de deserciones. No recuerdo cuántos serían, pero sí tengo claro que la mayoría de ellos jamás volvió a sus regimientos y, lo más seguro, es que formaron familia en el Perú». ${ }^{84}$ Aquello, sin duda propició entre algunos padres chilenos la oportunidad de establecer lazos afectivos con sus hijos ilegítimos. Sin embargo, también pudieron

${ }^{83}$ Mannarelli 1993: 231.

${ }^{84}$ Parvex 2015: 209. 
ser muchos los que no estaban interesados en reconocer a sus hijos por tener como prioridad regresar a su país.

\section{LOS «HIJOS DE LA GUERRA»: ¿PERUANOS O CHILENOS?}

La identidad de los «hijos de la guerra» no solo se determinaba por su estado de legítimos o ilegítimos, sino por su nacionalidad: ¿¿fueron considerados peruanos o chilenos? Este asunto debió quedar mucho más claro al finalizar la guerra. Al igual que en el caso de la legitimidad, las fuentes principales para desarrollar el presente apartado serán las Constituciones y Códigos Civiles vigentes en Perú y Chile en aquella época.

Desde la perspectiva peruana, según lo estipulado en el Código Civil de 1852, existen los siguientes medios para obtener la ciudadanía: por nacimiento, extracción o domicilio. No obstante, cada pueblo, según sus leyes, podía definir cuál debía ser válido en su territorio. Respecto a ello, Andrés Bello comenta que la adquisición de la ciudadanía por nacimiento era la más natural. ${ }^{85}$ Así, el hecho de haber nacido en el territorio era suficiente para conferir la nacionalidad al hijo de extranjero. ${ }^{86}$ En el Código Civil de 1852, se establece que la Constitución designa quiénes son peruanos o extranjeros. ${ }^{87}$ Sobre esto, la Constitución de 1860 señala que son peruanos por nacimiento: 1) «Los que nacen en el territorio de la República»; 2) «Los hijos de padre peruano o de madre peruana, nacidos en el extranjero, y cuyos nombres se hayan inscrito en el Registro Cívico»; y 3) «Los naturales de la América Española y los españoles que se hallaban en el Perú cuando se proclamó y juró la Independencia, y que han continuado residiendo en él posteriormente». ${ }^{88}$ Mientras, por naturalización, son peruanos: «Los extranjeros mayores de veintiún años residentes en el Perú, que ejercen algún oficio, industria o profesión y que se inscriben en el Registro Cívico en la forma de determinada por la ley». ${ }^{89}$

\footnotetext{
${ }^{85}$ Bello 1873: 80-81.

${ }^{86}$ Ib.: 80.

${ }^{87}$ Código Civil del Perú de 1852 [s.a.]: 16.

${ }^{88}$ La Constitución y leyes orgánicas del Perú 1869: 10.

${ }^{89} \mathrm{Ib}$.
} 
Desde la perspectiva chilena, se establecen medios similares. Según el Código Civil de 1857, son chilenos aquellos a los que la Constitución designa como tales; los demás son extranjeros. ${ }^{90} \mathrm{~A}$ su vez, la Constitución de 1833 señala que son chilenos: 1) «Los nacidos en el territorio de Chile»; 2) «Los hijos de padre o madre chilenos, nacidos en territorio extranjero, por el sólo hecho de avecindarse en Chile»; 3) «Los extranjeros que, profesando alguna ciencia, arte o industria, o poseyendo alguna propiedad raíz, o capital en giro, declaren ante la Municipalidad del territorio en que residan, su intención de avecindarse en Chile, y hayan cumplido diez años de residencia en el territorio de la República; bastarán seis años de residencia, si son casados y tienen familia en Chile, y tres años si son casados con chilena»; y 4) «Los que obtengan especial gracia de naturalización por el Congreso». ${ }^{91}$ De esta manera, podemos proponer algunas situaciones. Por un lado, en el caso de los chilenos civiles residentes en el Perú desde antes de la guerra, sus hijos podían ser considerados ante la ley como peruanos por derecho de nacimiento. Por otro lado, en el caso de los chilenos que llegaron a Lima con el ejército de ocupación y que retornaron a Chile con sus hijos nacidos en Perú, aquellos pudieron ser considerados chilenos.

La legitimidad también era una variable importante en la definición de la nacionalidad de los infantes. Según Bello, los niños de padres extranjeros adoptaban la ciudadanía del padre hasta que cumplían la mayoría de edad para manifestar su propio deseo de tener la misma ciudadanía del padre o no. No obstante, en algunos países, la dependencia de la condición del padre se cumplía para hijos legítimos y naturales; mientras que un hijo ilegítimo debía seguir la condición de la madre. ${ }^{92}$ En ese sentido, de cumplirse esto en Perú y Chile, dado que hemos encontrado en los registros a niños legítimos y naturales, podemos proponer que, en el caso de los chilenos que regresaban a su país con su familia peruana, aquellos podían escoger la ciudadanía chilena para sus hijos hasta que alcanzaran

${ }^{90}$ Código Civil de Chile de 1857 1961: 63.

${ }^{91}$ Constitución politica de la República de Chile 1906: 6-7.

92 Bello 1873: 82 y 80 . 
la mayoría de edad. A partir de aquel momento, al dejar de depender del padre, los hijos podían manifestar si deseaban seguir siendo chilenos o adquirir la ciudadanía peruana por derecho de nacimiento. En el caso de los ciudadanos chilenos residentes en Lima y naturalizados, sus hijos serían peruanos por derecho de nacimiento. De no estar naturalizados, podían elegir qué ciudadanía tener.

Para concluir el presente apartado, asumiendo que la mayoría de aquellos «hijos de la guerra» se quedaron en Lima, es conveniente mencionar un último aspecto respecto a su probable imagen o valoración en la sociedad. A pesar de lo estipulado por la ley respecto a la ciudadanía, surge la interrogante sobre si fueron vistos como parte de la comunidad o con recelo. En diversos estudios sobre niños producto de uniones entre soldados extranjeros y mujeres locales en contextos de ocupación militar, se ha demostrado que aquellos fueron tratados como parias por sus conciudadanos. Entre los más destacados, contamos con el estudio de Fabrice Virgili en el que muestra «la prevalencia de la estigmatización, el rechazo de las madres y las familias de los nińos, la falta de aceptación por parte de las comunidades locales, dejándoles la sensación de que nacer ha sido su crimen». ${ }^{93}$ En nuestro caso, por el momento es difícil acercarnos a este aspecto de la vida cotidiana de los niños peruano-chilenos, ${ }^{94}$ pues no contamos con fuentes personales a diferencia de los estudios sobre «los hijos de la guerra» en conflictos militares más recientes. ${ }^{95}$ Sin embargo, el rechazo hacia aquellos niños y

${ }^{93}$ Comentario de Mochmann, Lee y Stelzl-Marx (2009: 266) sobre el trabajo de Virgili (2009).

${ }^{94} \mathrm{Si}$ bien, como se ha comentado, los niños producto de aquellas relaciones sufren de estigmatización, son las madres quienes sufren el ataque directo (Mochmann, Lee, Stelzl-Marx 2009: 272). Son conocidos los castigos propinados a mujeres locales que se involucraron con soldados extranjeros en contextos de ocupación militar, especialmente el rapado a mujeres francesas gracias a las investigaciones de Virgili (2000), Capdevila y Virgili (2000), Bard (2000), Rouquet (2010) y otros.

${ }^{95}$ Después de la Segunda Guerra Mundial, los investigadores tienen acceso a fuentes como documentación proporcionada por organizaciones dedicadas a los hijos nacidos de la guerra, reportes de los medios de comunicación, biografías y autobiografías, fotografías y cartas, otra información de testigos y datos estadísticos (Mochmann, Lee y Stelzl-Marx 2009: 273-274). 
sus familias es una posibilidad que no debe ser descartada. Efectivamente, en años posteriores a la guerra del Pacífico, ser descendiente de chilenos pudo ser considerado un rasgo negativo, sobre todo en el contexto en el que las relaciones diplomáticas se tornaron tensas entre Perú y Chile, debido a la resolución pendiente sobre el destino de las provincias de Tacna y Arica. Podemos tomar como ejemplo el caso del empresario y político Ántero Aspíllaga, cuyo padre era un hacendado chileno. En el contexto de las elecciones de 1912, sus opositores utilizaron su origen para desprestigiarlo. En el acta de adhesión a Guillermo Billinghurst de los pobladores de Carhuas, se comenta lo siguiente: «la patria, que se veía amenazada de caer en manos mercenarias como las de don Ántero Aspíllaga que no puede ser buen patriota, siendo hijo de chileno». ${ }^{96}$

\section{CONCLUSIONES}

El nacimiento de niños peruano-chilenos fue una de las inevitables consecuencias sociales de la ocupación de Lima (1881-1883) que no debemos ignorar, pues los «hijos de la guerra» son un aspecto cada vez más considerado en el estudio de los conflictos bélicos. A través de este primer acercamiento al tema, hemos de reconocer los siguientes aspectos de la situación social de aquellos niños. En primer lugar, la condición de estos infantes estuvo marcada principalmente por la ilegitimidad, la cual atravesó los diferentes estratos sociales. Sin duda, el alto porcentaje de ilegitimidad se debió a la crisis generada por la guerra. Sin embargo, no se puede descartar el hecho de que aquel fue un aspecto que caracterizó a las sociedades peruana y chilena en la segunda mitad del siglo XIX, y que esta se acrecentó por la guerra. Resulta muy probable que después de la guerra la mayoría de estos infantes hayan tenido que cargar con el estigma de la ilegitimidad; las niñas eran especialmente vulnerables dado que resultaron ser las más numerosas entre los «hijos de la guerra». No obstante, gracias a mecanismos de ascenso social como el matrimonio, aquella condición podría ser superada. 
En segundo lugar, a través de casos de reconocimiento de algunos de estos «hijos de la guerra» en las partidas de bautizo, se puede determinar que la ilegitimidad no implicó necesariamente un obstáculo en las relaciones entre los padres chilenos y sus hijos. En tercer lugar, en lo que respecta a la nacionalidad de estos niños, existe la posibilidad de que los que permanecieron en el Perú hayan podido ser considerados peruanos por la ley, pero también es probable que sufrieran algún tipo de sanción social por sus orígenes. En caso de ser llevados a Chile por sus padres, probablemente fueron considerados chilenos. No obstante, según la ley, los niños en ambas circunstancias, al alcanzar la mayoría de edad, podían elegir con qué nacionalidad identificarse.

En el presente artículo, hemos podido brindar principalmente un perfil cuantitativo del tema y presentar algunas lecturas en torno a la forma en la que aquellos niños se relacionaron con sus padres chilenos y madres peruanas en este contexto tan particular, así como la forma en la que pudieron ser valorados en la sociedad limeña durante y después de la ocupación. Ante ello, esperamos, en una futura investigación, poder resolver los aspectos pendientes de este interesante tema. Por ejemplo, es relevante preguntarnos si aquellos niños sufrieron algún tipo de represalia por sus orígenes, si un número considerable de ellos fueron llevados a Chile o si los que se quedaron de Lima siguieron teniendo contacto con los padres que retornaron a su país después de la guerra, entre otras interrogantes.

\section{BIBLIOGRAFÍA}

Aguilar Rojas, Gonzalo. 2012. La administración de justicia en Lima durante la ocupación chilena (1881-1883). Tesis de Maestría en Política Jurisdiccional. Lima: Pontificia Universidad Católica del Perú.

Basadre Grohmann, Jorge. 2005. Historia de la República del Perú (1822-1933). Lima: El Comercio, 18 vols.

Bard, Christine. 2000. «El triunfo de la defensa de la familia» En Bard, Christine (ed.). Un siglo de antifeminismo. Madrid: Biblioteca Nueva, 147-166.

Barreto Valinotti, Ana Montserrat. 2013. Las mujeres. Asunción: El Lector. Bello, Andrés. 1873. Principios de derecho internacional. París: Lib. Garnier Hnos. Brel Cachón, María Pilar. 1999. "Comparación de los libros parroquiales y de los registros civiles. Una aproximación a la validez de las fuentes demográficas a 
finales del siglo XIX». Boletin de la Asociación de Demografía Histórica. Vol. XVII, núm. 2: 91-114. https://dialnet.unirioja.es/descarga/articulo/241767.pdf Burke, Peter. 2000. Historia y teoría social. México, D. F.: Instituto de Investigaciones Dr. José María Mora.

Capdevila, Luc y Fabrice Virgili. 2000. «La depuración y el rapado de las colaboracionistas ¿es antifeminismo?». En Bard, Christine (ed.). Un siglo de antifeminismo. Madrid: Biblioteca Nueva, 217-226.

Chambers, Sarah C. 2003. De súbditos a ciudadanos: honor, género y política en Arequipa, 1780-1854. Lima: Red para el Desarrollo de las Ciencias Sociales en el Perú.

Clavero, José González. 1885. Demografía en Lima 1884. Lima: Imprenta de J. Francisco Solís.

Código Civil de Chile de 1857. 1961. Madrid: Instituto de Cultura Hispánica. Código Civil del Perú de 1852. [s.a.]. Lima: M.A. Fuentes \& B. Gil, Editores.

Constitución política de la República de Chile jurada i promulgada el 25 de mayo de 1833 con las reformas efectuadas hasta el 26 de junio de 1893. 1906. Santiago de Chile: Imprenta Gutenberg Ahumada.

Fuentes, Manuel Atanasio. 1988. Lima: apuntes históricos, descriptivos, estadísticos y de costumbres. Lima: Banco Industrial del Perú.

Godoy Orellana, Milton. 2017. «Hijos de padres al servicio de nuestra república. El Estado de Chile y los hijos de funcionarios chilenos nacidos durante la ocupación de Lima, 1881-1883». Santiago de Chile [inédito].

Guerra Martinière, Margarita. 1991-1996. La ocupación de Lima (1881-1883). Lima: Pontificia Universidad Católica del Perú e Instituto Riva-Agüero, 2 vols. Holguín, Oswaldo. 1972-1974. «Aspectos de la vida religiosa en Lima durante la ocupación chilena (1881-1883)». Boletín del Instituto Riva-Agüero. Núm. 9: 168-171.

Huamán Guardia, Rosa Grimalda. 2009. La ciudad ante la guerra: mujeres, familia y sociedad en Lima durante durante la Guerra del Pacífico. Tesis de Licenciatura en Historia. Lima: Pontificia Universidad Católica del Perú

Hünefeldt, Christine. 2000. Liberalism in the bedroom: quarreling spouses in Nineteenth-Century Lima. University Park: Pennsylvania State University Press.

La Constitución y leyes orgánicas del Perú dadas por el Congreso de 1860. 1869. Lima: Imprenta del Estado.

Lockhart, James. 1982. El mundo hispanoperuano, 1532-1560. México, D. F.: Fondo de Cultura Económica.

Mannarelli, María Emma. 1993. Pecados públicos: la ilegitimidad en Lima, siglo XVII. Lima: Flora Tristán.

2004. «Vínculos familiares y fronteras de lo público y lo privado en el Perú». En Rodríguez, Pablo (coord.). La familia en Iberoamérica 1550-1980. Bogotá: Convenio Andrés Bello, 327-367. 
Mannarelli, María Emma y Pablo Rodríguez Jiménez (coords.). 2007. Historia de la infancia en América Latina. Bogotá: Universidad Externado de Colombia.

Mc Evoy, Carmen. 2000. "Bella Lima ya tiemblas llorosa del triunfante chileno en poder': una aproximación a los elementos de género en el discurso nacionalista chileno». En Lohmann Villena, Guillermo (ed.). Homenaje a Félix Denegri Luna. Lima: Pontificia Universidad Católica del Perú, 469-490.

Middendorf, Ernest W. 1973. Perú: observaciones y estudios del pais y sus habitantes durante una permanencia de 25 años. Lima: Universidad Nacional Mayor de San Marcos.

Ministerio de Gobierno, Policía y Obras Públicas. 1878. Censo general de la República del Perú formado en 1876. Lima: Imprenta del Teatro, 7 vols.

Mochmann, Ingvill C.; Lee, Sabine y Barbara Stelzl-Marx. 2009. "The children of occupations born during the Second World War and beyond: an overview». Historical Social Research. Vol. 34, núm. 3: 263-282. http://www.ssoar.info/ ssoar/bitstream/handle/document/28728/ssoar-hsr-2009_no_3_no_129mochmann_et_al-the_children_of_occupations_born.pdf?sequence $=1$

Mora Ponce, Margarita. 2010. «Los nińos héroes durante la guerra con Chile». San Marcos al día. Núm. 224: 11. http://www.unmsm.edu.pe/sanmarcosaldia/ semanarios/224.pdf

2011. «Testimonios de niños en Lima durante la guerra con Chile». San Marcos al día. Núm. 229: 15. http://www.unmsm.edu.pe/sanmarcosaldia/ semanarios/229.pdf

Mühlhäuser, Regina. 2005. «Between Extermination and Germanization: Children of German Men in the 'Occupied Eastern Territories', 1942-1945». En Ericsson, Kjersti y Eva Simonsen (eds.). Children of World War II: The Hidden Enemy Legacy. Oxford y Nueva York: Berg, 167-189.

Panfichi, Aldo. 1995. «Urbanización temprana de Lima, 1535-1900». En Panfichi, Aldo y Felipe Portocarrero. Mundos interiores: Lima, 1850-1950. Lima: Universidad del Pacífico, 15-42.

Parvex, Guillermo. 2015. Un veterano de tres guerras. Recuerdos de José Miguel Varela. Santiago de Chile: Academia de Historia Militar de Chile.

Picaper, Jean-Paul y Ludwi Norz. 2004. Enfants Maudits. París: De Syrtes.

Pollock, Linda A. 1990. Los niños olvidados. Relaciones entre padres e hijos de 1500 a 1900. México, D. F.: Fondo de Cultura Económica.

Potthast, Bárbara. 1998. «Hogares dirigidos por mujeres e hijos naturales. Familia y estructuras domésticas en el Paraguay del siglo XIX». En Cicerchia, Ricardo (comp.). Formas familiares, procesos históricos y cambio social en América Latina. Quito: Abya-Yala, 131-148.

Ramos, Carlos. 2005. Historia del derecho civil peruano: siglos XIX y XX. Vol. 2 La codificación del S.XIX: los Códigos de la Confederación y el Código Civil de 1852. Lima: Pontificia Universidad Católica del Perú. 
Ramón Joffré, Gabriel. 2004. «El guión de la cirugía urbana: Lima 1850-1940». En Ensayos en Ciencias Sociales: premio nacional en ciencias sociales. Lima: Universidad Nacional Mayor de San Marcos, 9-33.

Rivera Serna, Raúl. 1984. «La ocupación chilena de Lima: aspectos político-administrativos». En La Guerra del Pacífico. Lima: Universidad Nacional Mayor de San Marcos, vol. 2, 1-43.

Rodríguez Díaz, Juan José. 2009. «El bello sexo en guerra: cultura política y género durante la Guerra del Pacífico». Illapa: revista latinoamericana de ciencias sociales. Año 2, núm. 5: 83-120.

Rojas Flores, Jorge. 2010. Historia de la infancia en el Chile republicano, 1810-2010. Santiago de Chile: Ocho libros.

Rosas Lauro, Claudia. 2007. «El derecho de nacer y de crecer: los nińos en la Ilustración: Perú, siglo XVIII». En Manarelli, María Emma y Pablo Rodríguez Jiménez (coords.). Historia de la infancia en América Latina. Bogotá: Universidad Externado de Colombia, 215-228.

Rouquet, François. 2010. «En la Francia del Mariscal». En Christine Fauré (dir.). Enciclopedia histórica y política de las mujeres: Europa y América. Madrid: Akal, 631-652.

Torrejón, Luis. 1995. "Lima 1912: el caso de un motín popular urbano». En Panfichi, Aldo y Felipe Portocarrero. Mundos interiores: Lima, 1850-1950. Lima: Universidad del Pacífico, 315-339.

Valle Vera, María Lucia. 2013. Relaciones entre chilenos y mujeres peruanas residentes en Lima durante la ocupación militar de la ciudad (1881-1883) a través de las fuentes parroquiales. Tesis de Licenciatura en Historia. Lima: Pontificia Universidad Católica del Perú.

Vergara Ormeño, Teresa. 2007. «Growing up indian: Migration, labor and life in Lima». En González, Ondina E. y Bianca Premo (eds.). Raising an Empire. Children and Youth in Early Modern Iberia and colonial Latin America. Albuquerque: University of New Mexico Press, 75-106.

. 2011. «Vivir y crecer en Lima: niños y jóvenes indígenas en el siglo XVII». En Rosas Lauro, Claudia (ed.). Nosotros también somos peruanos: la marginación en el Perú, siglos XVI a XXI. Lima: Pontificia Universidad Católica del Perú, 95-114. Vergara Quiroz, Sergio. 1993. Historia social del ejército de Chile. Santiago de Chile: Universidad de Chile, 2 vols.

Virgili, Fabrice. 2000. La France virile: Des femmes tondues à la Libération. París: Edition Payot. .2009. Naître ennemi: Les enfants de couples franco-allemands nés pendant la Seconde Guerre Mondiale. París: Edition Payot.

Fecha de recepción: 12/IX/2016 Fecha de aceptación: 17/XI/2016 